\title{
Missing Girls in Nepal: An Emerging Challenge
}

\author{
Dipak Subedi \\ BPH $22^{\text {nd }}$ Batch \\ dipaks119@yahoo.com
}

\section{Introduction}

There is a little-known battle for survival going in some parts of the world. Those at risk are baby girls, and the casualties are in the millions each year. The weapons being used against them are prenatal sex selection, abortion and female infanticide - the systematic killing of girls soon after they are born.

Discrimination against girls may begin in the womb. Sex selection can take place before a pregnancy is established, during pregnancy through prenatal sex detection and selective abortion, or following birth through infanticide or child neglect. Prenatal sex selection meant that countless others were denied the right even to exist. Baby girls also die through deliberate neglect and starvation.

In some countries, a strong and traditional preference for sons combined with population control measures, has led to the elimination of millions of girls through prenatal sex selection often for family balancing purpose. The strong society induced desire to have sons often leads women to select for abortions after determining the sex of the fetus that is, if it turns out to be a girl. In countries like India and China tens of millions of girls have died as young children due to neglect, have been killed as infants, or were never born due to sex-selective abortions.

Sex selective abortion is intended to increase a couple's chances of having at least one boy. If the families already have female child, there is high chance of missing girls. Parents may accept a daughter first time round but will do anything to ensure their next and probably last child is a boy. While many families repeatedly conceive in hopes of having a son, others resort to sex-selective abortion.

Despite women being biologically predisposed to live longer than men, sex-specific abortions, infanticide, or systematic discrimination against women have decreased the ratio of women to men. Prenatal sex selection was probably the primary cause, if not the sole cause, for the continuous rise of the sex ratio at birth.

\section{Scenario}

According to UN statistics, there are 100 million girls missing around the world. Many of them are left on the sides of roads, drowned, maimed and thrown in trash bins. But even more of them have been aborted. The practice of couples in Asia aborting female fetuses if they don't yet have a male child is becoming more common and widespread.
In Asia, at least 60 million girls are "missing". In some countries, sex selection is more common in cities, where technologies such as amniocentesis and ultrasound are readily accessible and open to misuse. In others, it occurs more commonly in rural areas, where the preference for sons is strong.

In Nepal, due to country's long standing patriarchal society son preference is very strong. UNICEF, estimates that 20 percent of the more than 70,000 abortions that take place in Nepal each year are carried out by women who prefer a son to a daughter.

In India, reports showed that more than 10 million girls have gone missing in the past 20 years. In China, the imbalance between the sexes was 108 boys to 100 girls for the generation born in the late 1980s; for the generation of the early 2000s, it was 124 to 100 . In some Chinese provinces the ratio is an unprecedented 130 to 100 . The destruction is worst in China but has spread far beyond. Other East Asian countries, including Taiwan and Singapore, former communist states in the western Balkans and the Caucasus, and even sections of America's population (Chinese- and Japanese-Americans, for example): all these have distorted sex ratios

\section{Causes}

The destruction of baby girls is a product of three forces: the ancient preference for sons; a modern desire for smaller families; and ultrasound scanning and other technologies that identify the sex of a fetus. In societies where four or six children were common, a boy would almost certainly come along eventually; son preference did not need to exist at the expense of daughters. But now couples want two children they will sacrifice unborn daughters to their pursuit of a son.

The traditional patriarchal society confers importance in the preference for sons over daughters. It is reinforced by the perception that daughters are an economic liability, either because of low expected contributions to family income or large dowry requirements. Need of hard physical labor in family or only son may inherit land also increase the chance of son preference. As it is assumed that a daughter is deemed to have joined another family on marriage and is lost to her parents, parents must rely on their sons to take care of them. As a Hindu saying puts it, "Raising a daughter is like watering your neighbours' garden." 
In Nepal, giving birth to a son enhances a woman's status within the family, whereas her inability to produce a male heir may result in humiliation, contempt, abuse, and abandonment. Men frequently blame their wives for not giving birth to a male child. In-laws may also openly threaten their daughters-in-law with ominous consequences if they are unable to produce a son. In abusive situations, a woman may be forced to undergo tests to identify the sex of her unborn child, and then coerced to abort if the fetus is female. Women may be beaten and/or divorced for not giving birth to sons. An abusive spouse may use the birth of a daughter as a pretext for violence towards his wife, and then be violent towards the unwanted daughter.

The global trend of fateful collision between overweening son preference, the use of rapidly spreading prenatal sexdetermination technology and declining fertility ultimately increasing chance of selective destruction of baby girls. In many places, sex selection has become a lucrative business for doctors and producers of medical equipment.

\section{Legal Provision}

In Nepal, the abortion was legalized in 2002. The law will allow the abortion in certain condition and sex selective abortion is punishable. Following the legalization sex selective seem to be rising in number. The combination of relaxed laws and the availability of ultrasound technology have given tens of thousands of women the opportunity to abort after learning the sex of the fetus. Sex-selective abortion remains illegal, but the procedure is common.

The use of sex-selective abortion was banned in India in 1994 and in China in 1995. It is illegal in most countries (though Sweden legalized the practice in 2009). But since it is almost impossible to prove that an abortion has been carried out for reasons of sex selection, the practice remains widespread. Though the Governments have banned the practice, and passed laws against discrimination and abandonment of girls, but the practice is deeply rooted.

\section{What will be the consequences?}

A continuing missing of girls has many potentially serious consequences. Many of the problems associated with sex selection will get worse over the next generation. The social consequences will become more evident because the boys born in large numbers over the past decade will reach maturity then. Meanwhile, the practice of sex selection itself may spread because fertility rates are continuing to fall and ultrasound scanners reach throughout the developing world.

Sex selection distorts natural sex ratios, varying in degree by country, state, culture, and religion. An imbalanced sex ratio perpetuates gender discrimination against women, contributes to poor health in women, and disrupts social and familial networks.

The shortage of women and girls in some Asian countries will have potential alarming on social repercussions, including increased demand for trafficking in women, whether for marriage or for sex work, and the worsening of their status overall.

In Nepal, sex-selective abortion is not yet an issue of major concern. However, in light of the legalization of abortion, easy availability of pre-natal sex-determination technologies and abortion clinics, as well as the religious and socioeconomic value given to sons, the demand for sex-selective abortion could increase in the coming years. In addition, the declining fertility levels and the pressure on couples to balance the sex composition of their children may contribute to further demand for pre-natal sex selection.

Chinese Academy of Social Sciences (CASS) estimated that within ten years from 2010, one in five young men would be unable to find a bride because of the dearth of young women a figure unprecedented in a country at peace.

\section{How to stop half the sky crashing down}

Baby girls are thus victims of a malign combination of ancient prejudice and modern preferences for small families. Female education, anti-discrimination suits and equal-rights rulings made son preference seem old-fashioned and unnecessary. All countries need to raise the value of girls. They should encourage female education; abolish laws and customs that prevent daughters inheriting property; get women engaged in public life. Women hold up half the sky. The world needs to do more to prevent a gendercide that will have the sky crashing down.

In Nepal, economic, cultural and religious practices make sons more desirable than daughters. After abortion got legalized here in 2002, as a result, the practice has become safer. Nepali women are largely deprived of decision-making roles when it comes to family planning. Married women are generally not allowed to use contraceptives without the approval of their husbands and families. But interestingly women use their increased autonomy to abort their daughters and select for sons, who enhance their social status. Particular attention will need to be given to empower women and to participate in decision making.

An essential element in efforts to reduce sex ratio imbalances are advocacy, sensitization and awareness-raising programmes conducted. By addressing and involving relevant social and other networks (such as health personnel and young women and men) these activities aim to change mindsets and attitudes towards girls, and to increase recognition of the value of girls and women in society.

Much can be done to this end through social movements and legislation to elaborate and implement policies to address the root causes of son preference - including policies on inheritance, dowry, financing old age and other personal security issues, education and the determination of surname. 


\section{Conclusion}

Missing girls are an increasing cause of concern in some South Asian, East Asian and Central Asian countries, particularly as they are indicative of persistent and underlying gender discrimination against girls and women. Such discrimination, and the intense pressure to produce sons, has serious and profound effects on the mental and physical health of women.

Eliminating the practice requires changes in the way girls and women are valued by society. The comprehensive approach that includes building media interest, creating community-based networks to advocate against the practice, sensitizing health providers and involving youth and other key stakeholders helps to mitigate the practice.

\section{References}

1. World Health Organization. Preventing gender-biased sex selection: an interagency statement - OHCHR, UNFPA, UNICEF, UN Women and WHO. Geneva: World Health Organization; 2011.

2. UNFPA. State of the world's population: The Promise of Equality: United Nations Population Fund.; 2005.

3. Sen AK. Missing women. BMJ 1992;304:586-7.

4. Sen AK. Missing women - revisited. BMJ 2003;327:1297-8

5. Jha P, Kesler MA, Kumar R, Ram F, Ram U, Aleksandrowicz L, et al. Trends in selective abortions of girls in India: analysis of nationally representative birth histories from 1990 to 2005 and census data from 1991 to 2011. Lancet. 2011 Jun 4;377(9781):1921-8.

6. Lamichhane P, Harken T, Puri M, Darney PD, Blum M, Harper CC, et al. Sex-selective abortion in Nepal: a qualitative study of health workers' perspectives. Womens Health Issues. 2011 May-Jun;21(3 Suppl):S37-41.

7. Smolin DM. The MIssing Girls of China: Population, Policy, Culture, Gender, Abortion, Abandonment, and Adoption in East-Asian Perspective. Selected Works; 2011 [cited 2011 September 6]; Available from: http:// works.bepress.com/david_smolin/9

8. CREHPA (2000). Unwanted Pregnancies, Sex Determination Tests and Sex-selective Abortion in Urban Areas of Nepal: Medical practitioners' perspectives. Centre for Research on Environment Health and Population Activities, Kathmandu.
9. Varkey S, Gupta SS. How gender (in)sensitive are the gender-related indices? Bulletin of the World Health Organization. 2005 December.

10. Government of Nepal (2003). National Safe Abortion Service Policy, 2060 B.S.

11. CREHPA. Sex Selection : Pervesiveness and preparedness in nepal. 4th Asia Pacific Conference on Reproductive and Sexual Health and Rights; India. Kathmandu, nepal: Center for Research on Environment, Health and Population Activities; 2007.

12. The worldwide war on baby girls: Technology, declining fertility and ancient prejudice are combining to unbalance societies. The Economist; 2010 [cited 2011 September 6]; Available from: http:// w w w . e c o n o m i s t . c o m / n o d e / 15636231 ?story_id=15636231.

13. Stop Sex Selective Abortion. Population Research Institute; [cited 2011 September 6]; Available from: http://www.pop.org/projects/stop-sex-selectiveabortion.

14. Brown D. Sex-selective abortion on rise in India among couples without boys. The Washington Post; 2011 [cited 2011 September 5]; Available from: http:// www.washingtonpost.com/world/sex-selectiveabortion-on-rise-in-india-among-couples-withoutboys/2011/05/23/AF91bHAH_story.html. 